\title{
América quarta pars: ¿isla o continente? EI debate conceptual sobre el estatus geográfico del Nuevo Mundo en el siglo XVI
}

\author{
Carla Lois \\ Universidad de Buenos Aires, Argentina \\ carlalois054@gmail.com
}

\begin{abstract}
Resumen
América fue incorporada en la bibliografía especializada del quinientos como la quarta pars o cuarta parte de un mundo, concebido como la articulación de otras tres (Europa, Asia y África). Sin embargo, pronto quedaría expuesta una tensión conceptual: mientras que las tres partes del viejo mundo eran piezas de una gran isla, la cuarta parte era una isla en sí misma. Este es un análisis del debate conceptual y las propuestas teóricas que plantearon alternativas para definir el estatus geográfico del Nuevo Mundo, y demostrará que esa discusión no solo afectó la definición de América, sino que también inauguró el concepto moderno de continente.
\end{abstract}

Palabras clave: cartografía, América, siglo XVI, isla, continente.

\begin{abstract}
Since the early 16th century, despite some exceptions, most scholars accepted that the oekumene involved three parts (Europe, Asia and Africa), and maps and books displayed America as the fourth part of the world. This idea of "fourth part" relied on the New World's huge size and its "original nature". However, many scholars noted that, while the traditional three parts were pieces of a single landmass, America appeared to be an island. Analyzing the interpretations of world geography at that time, I will focus on the essays that tried to provide a theoretical framework to incorporate these new discoveries into a comprehensive world view. I will argue that this discussion affected not only the geographical definition of the New World, but a new and modern idea of continent.
\end{abstract}

Key words: cartography, America, 16th century, island, continent. 


\section{Introducción. Pensar la geografía en el quinientos}

Un gran número de imágenes sobre América apareció en la Europa del quinientos: iconografías, paisajes, mapas, retratos, escenas costumbristas y estampas monstruosas pusieron en circulación —en el Viejo Mundo - una masa de ideas sobre el Nuevo Mundo ${ }^{1}$. Durante los 500 años siguientes no cesaron de aparecer estudios que leyeron, revisaron, analizaron, criticaron e interpretaron esas imágenes. Muchos de ellos ofrecen una historia acerca de cómo se fue "develando" una geografía incierta, explorada casi a ciegas por cientos de personas durante el siglo XVI. En particular, los mapas del siglo XVI han sido analizados como indicios de esa geografía imaginaria ${ }^{2} \mathrm{y}$, a menudo, han sido interpelados en clave retrospectiva (esto es, una ordenación cronológica de los mapas, enfocada en los "aciertos" y los "errores" cometidos en el proceso de mapeado de la "era de los descubrimientos" 3 ), una reconstrucción de los pasos que se dieron para llegar a la geografía que hoy conocemos $^{4}$. Sin embargo, el proceso en medio del cual América tomó la forma moderna

1 Usaremos las expresiones Nuevo Mundo y América como designaciones genéricas para referirnos al actual continente americano, sin que ello pretenda remitir a un referente fijo y predeterminado ni, necesariamente, al actual continente americano. En parte porque hay abundante bibliografía y en parte por la naturaleza de este trabajo, evitaremos aludir al debate de los topónimos utilizados para nombrar al conjunto de las tierras descubiertas (así como también el uso de estos nombres aplicados a otros objetos geográficos) y nos centraremos en el debate conceptual que apuntaba a responder las preguntas: ¿qué clase de tierra son las que forman el Nuevo Mundo? ¿Esas tierras cambian la geografía del mundo conocido? El presente trabajo es el resultado de una investigación más amplia, cuyo principal objetivo es indagar los modos como se representó el hemisferio sur en mapas del mundo y libros de ciencia (obras catalogadas bajo los rótulos de diversas artes liberales que, implícita o explícitamente, tematizaron, interpretaron o se interrogaron sobre el mundo geográfico) en el Renacimiento. Ese trabajo fue realizado gracias al apoyo de la beca Jeannette D. Black Memorial en la John Carter Brown Library.

2 Nos referiremos a las geografías imaginarias en los términos que Edward Said utilizó en Orientalismo: "La práctica universal de establecer en la mente un espacio familiar que es 'nuestro' y un espacio no familiar que es el 'suyo' es una manera de hacer distinciones que pueden ser totalmente arbitrarias. Utilizo la palabra ‘arbitrario’ porque la geografía imaginaria que distingue entre 'nuestro territorio y el territorio de los bárbaros' no requiere que los bárbaros reconozcan esta distinción" (87).

3 Existe un consenso casi generalizado en designar con la expresión "era de los descubrimientos" a la expansión marítima europea de la segunda mitad del siglo XV y la primera mitad del siglo XVI, aunque algunos autores refieren diversos cortes cronológicos. Por ejemplo, Brotton designa así al periodo comprendido entre 1480 y 1540 (21). Otros autores le dan a este proceso continuidad hacia el pasado y hacia el futuro. David Livingstone sitúa la Age of Reconaissan$c e$ entre Enrique el Navegante y las primeras décadas del siglo XVII. John Parry extiende el periodo de expansión europea a su expresión máxima y lo fija entre 1415-1715. Más allá de sus diferencias, todos ellos recuperan el descubrimiento de América como uno de los hitos más importantes de ese proceso.

4 En los libros consagrados a la historia de la cartografía la sucesión cronológica ha sido uno de los principales criterios de organización, especialmente en aquellos casos en que la obra comprende largos periodos, y cuya narrativa demuestra la progresión hacia imágenes más precisas 
de continente o "parte" del mundo, lejos de ser un camino lineal, fue un desafío intelectual sin precedentes. Por lo tanto, en lugar de desandar el camino desde el presente, nos situaremos en las reflexiones sobre la naturaleza de la nueva geografia, surgidas al mismo tiempo que se llevaban a cabo las exploraciones sobre esas geografías.

Una parte importante del debate sobre la naturaleza geográfica del Nuevo Mundo buscó dirimir si se trataba de una isla o un continente ${ }^{5}$. No se trataba de una dicotomía conceptual del todo original: mucho antes de que Cristóbal Colón desembarcara en mares americanos, los savants se habían preguntado si los antípodas eran islas o continentes ${ }^{6}$. En este sentido, es posible pensar que la envergadura que fue tomando el descubrimiento del Nuevo Mundo en el mundo europeo a lo largo del quinientos reactivó (y amplificó) un debate geográfico cuyas claves ya eran, en cierto sentido, familiares entre los eruditos. Por otra parte, dentro de los términos en que discurrió esa polémica en relación con el Nuevo Mundo, ninguna de las dos opciones impugnaba el estatus de Cuarta Parte. Por ende, la relevancia de esta discusión no residiría tanto en los intentos que se hicieron por adscribir una categoría geográfica al Nuevo Mundo (ni en sus aciertos o sus errores) como en la impronta que esos esfuerzos dejaron en el campo de las ideas geográficas. Dicho en otros términos, la evidencia geográfica asociada al descubrimiento europeo de América, junto con la necesidad de "hacer inteligible su presencia en el cuadro de la herencia de la cultura europea" (Randles 129), habría instalado una preocupación — hasta entonces, inédita - por sistematizar un andamiaje conceptual coherente de términos geográficos, cuyas resonancias todavía participan del campo teórico de la disciplina geográfica contemporánea.

Este trabajo examina el debate teórico subyacente en la tensión dicotómica isla vs. continente en las obras geográficas renacentistas que trataban de dilucidar la naturaleza geográfica del Nuevo Mundo. Si aceptamos a priori que uno de los rasgos que caracterizan a la geografía del quinientos es, precisamente, el alto nivel de incertidumbre, una revisión crítica de los derroteros que siguió una de las polémicas geográficas de la época (esto es, el debate conceptual acerca del estatus geográfico del Nuevo Mundo puesto en circulación en un amplio y heterogéneo corpus de literatura geográfica durante el siglo XVI) permitirá indagar no solo al-

(por ejemplo: Whitfield, Nebenzhal y Vargas). Sin embargo, el orden cronológico no siempre ha implicado una lectura evolutiva del pasado; es el caso de la ineludible obra cartobibliográfica de Rodney Shirley y del monumental proyecto editorial del grupo History of Cartography, iniciado en los años ochenta en la Universidad de Wisconsin. Además, un conjunto de publicaciones aparecidas en las últimas décadas demuestra que la historia de la cartografía puede ser narrada con otros criterios alternativos (Wolff, Broc y Jacob).

5 W. Randles (129-158) ha reseñado los textos renacentistas que se expidieron acerca del estatus insular o continental del Nuevo Mundo.

6 Véase Vignolo, especialmente el apartado “Les antipodes: archipiel ou continente?". 
gunos aspectos del desafío intelectual que implicó hacer inteligible América, sino también el origen de la sistematización de los conceptos geográficos modernos.

\section{La organización de las tierras emergidas}

La recurrencia del uso de términos geográficos tales como isla, península, istmo y continente sugiere que hacia el siglo XVI existía gran consenso acerca de cierta tipología estándar para clasificar las tierras emergidas. Sin perjuicio de la polisemia que tenía cada uno de estos términos, a mediados del quinientos se registra una tendencia a reunirlos en una suerte de glosario básico, que organizaba las tierras emergidas desde un punto de vista eminentemente geográfico. Una premisa implícita de ese sistema terminológico era que las categorías eran mutuamente excluyentes y que toda porción terrestre podría ser clasificada en alguna de ellas. El glosario en cuestión explicitaba las propiedades específicas de cada tipo, acompañadas por ejemplos, tal como puede apreciarse en la siguiente cita:

\section{Cómo difieren isla, península, istmo y continente. Capítulo 17}

La tierra se parte por las aguas en cuatro maneras. Porque o cerca totalmente la tierra y se dice Isla, como Rodas, Socilia, Corecega, Taprobana, Java, America, Anglia, Islandia.

O es Península, que es parte de la tierra, la cual no es totalmente isla, ni tierra firme, sino cerrada casi por todas partes, y queda un pedazo de tierra, por la cual se junta con la tierra firme. Y son cuatro las principales penínsulas en el mundo. La primera es la que los Griegos llamaban Peloponeso. [...] La otra se dice Cimbrita en el mar de Alemania. La otra se dice Taurica Chersoneso $[\ldots]$.

$\mathrm{O}$ es Istmo, que se dice una parte de tierra comprendida entre dos mares: y propiamente es camino al Chersoneso o Península, como el Istmo Corintiaco, Cayo Príncipe, Domitio, y Nero infelicísimamente atentaron cortar, según cuenta Plinio en su natural historia. También las espadas de Arabia, [...] y toda Italia, se dirán Istmo.

O Continente, que se dice toda tierra firme, que no es Isla, ni Península, ni Istmo, y puesto que reciba en sí algunos senos de mar y puertos, pero toda está pegada entre sí. (Apiano y Frisius 29)

Y, vale agregar, el "continente" aparecía generalmente dividido en tres partes: Europa, Asia y África (aunque esta última solía aparecer bajo diferentes formas y denominaciones ${ }^{7}$ ). En tanto la idea de que el mundo era el resultado "de la unión

Si bien numerosos mapas medievales muestran a África como una tercera parte y, siguiendo una interpretación cristiana, la parte africana solía ser correspondida con el tercer hijo de Noé, hacia el siglo XV ello no implicaba necesariamente que África fuera una parte separada y dis- 
y mixión de tierra y agua" (Chaves 61) estaba ampliamente instalada entre los humanistas, la mayor parte de los libros que describían "el mundo" se ocupaban en forma separada de las aguas y de las tierras, y desarrollaba la descripción de las tierras siguiendo casi invariablemente un ordenamiento según sus partes. Por lo general, el tema de la partición o división de las tierras emergidas se introducía estableciendo un claro y explícito contraste entre el mundo conocido por los antiguos y el mundo de los modernos, fundamentalmente haciendo hincapié en la cantidad de partes y refiriendo la incorporación del Nuevo Mundo.

Ahora bien: lejos de ser una cita original de Gemma Frisus, esta clasificación de las tierras en isla, península, istmo y continente es un esquema que aparece repetido en muchos libros de cosmografía, geografía y ciencias durante el siglo XVI. Dado que tampoco era novedoso ${ }^{8}$, podemos sugerir que este renovado interés por definir el estatus geográfico de las tierras estaría asociado a la necesidad de explicar la naturaleza de las que hoy conocemos como tierras americanas. Si se considera que hasta el siglo XVIII no hubo certeza alguna respecto a la conexión entre América y Asia ${ }^{9}$, esa misma incertidumbre puede resumirse en la siguiente pregunta: ¿América debía ser incluida en la categoría de isla o de continente?

\section{Quarta pars: ¿isla o continente?}

Muy pronto el Nuevo Mundo fue aceptado como una cuarta parte que se agregaba a un mundo tradicionalmente concebido como la articulación de tres (Asia, África y Europa), lo que mantuvo invariable el esquema geográfico. La afirmación del mundo cuatripartito solía destacarse entre los primeros capítulos de las obras, usualmente bajo un título que hacía alusión a la división o partición de las tierras; y fue ampliamente repetida, con mínimas variaciones, por autores de las más variadas nacionalidades y tradiciones. Ahora bien, la generalización de esta fórmula no debe hacernos perder de vista que la adición de esta cuarta parte no fue ni inmediata al descubrimiento europeo de América ni inequívocamente entendida. Por eso, más interesante que reparar en el hecho de que casi todos los libros

tinta de Europa. Además, aparecía bajo diversas designaciones (Etiopía, Libia, etc.) y ocupando superficies variables. Sobre la emergencia de África como continente, véase Relaño, 2002.

8 Un texto medieval reproducido bajo el título Les merveilles du Monde ou Les secrets de l'histoire naturelle define isla de la siguiente manera: "Ile c'est une porcion de terre habitable, laquelle est toure environnée de eaus" (tomado de la edición facsimilar de Anne-Caroline Beagendre 1996: 45). El texto corresponde al BNF Manuscrit francais 1377-1379. El uso del término "península" puede rastrearse hasta Isidoro: en su Etymologiae 14.4.14 dice: "Achaia ab Achaeo rege et urbs et provincia appellata. Haec pene insula est; nam absque septentrionali parte, qua Macedoniae iungitur, undique septa est mari".

9 El explorador danés Vitus Bering ratificó la existencia de un estrecho que separa las tierras asiáticas de las americanas en su expedición de 1728. 
editados y reeditados durante el quinientos incluyeron al Nuevo Mundo ${ }^{10}$, parece serlo revisar los modos como esa inclusión fue realizada (ya que fueron muy variables $)^{11}$. Esas variaciones en los modos como la quarta pars fue "insertada" en la geografía del mundo fueron un síntoma de las dificultades y las dudas que los humanistas tenían para identificar la naturaleza geográfica del Nuevo Mundo. Tales incertidumbres se manifestaron, fundamentalmente, en dos planos: por un lado, en el lugar y la jerarquía atribuidos a América en las obras de geografía y ciencias, específicamente en la posición relativa y el rango de la cuarta parte en relación con las otras tres ${ }^{12}$; por otro lado, en las variaciones, las ambigüedades

10 Algunos, muy pocos, siguieron sin hacer alusión a América: la Division du Monde, publicada en 1539 por el ingeniero militar y cartógrafo Jacques Signot, "simplemente olvida a América" (Broc 66).

11 Excluimos de este análisis los libros cuyo tema principal ha sido el Nuevo Mundo o alguno de sus tópicos. Examinamos los libros que describen el mundo concebido como una totalidad para revisar las estrategias textuales puestas en juego para incorporar a América en un esquema geográfico englobante y totalizador. Para mayor detalle sobre el corpus de las fuentes analizadas, véase la lista completa al final.

12 Dentro del nutrido elenco de obras clásicas que expandieron drásticamente su circulación gracias a la imprenta, muchos libros de las más variadas artes liberales hacían referencia al mundo (su origen, su esencia, su organización, etc.). Los libreros y los editores, como activos impulsores y agentes de un creciente mercado editorial, rápidamente advirtieron que era posible ampliar la demanda a partir de ampliar la oferta ofreciendo productos "cada vez más modernos" con información actualizada. En ese horizonte se vieron en la necesidad de incorporar, paulatinamente, a América en sus ediciones - tanto en sus textos como en sus imágenes-. Sin embargo, esas adiciones rara vez implicaron una reformulación radical del texto original. Más bien, consistían en el agregado de algo sobre América al final del texto, en lo que parece haber sido tanto una actualización forzosa como una solución de compromiso. Esto parece corresponderse con una reacción señalada por muchos especialistas: el prestigioso hispanista John Elliott apunta que "la resistencia de los cosmógrafos o de los filósofos a incorporar a su trabajo la nueva información que les proporcionaba el descubrimiento de América no es más que un ejemplo del amplio problema que origina la proyección del Nuevo Mundo sobre el Viejo" (Elliott 32) y no duda en atribuir esa resistencia al movimiento renacentista, presentado en general como liberador del "corset medieval": "el Renacimiento suponía en algunos aspectos, al menos en su primera etapa, una cerrazón más que una apertura del pensamiento. La veneración por la Antigüedad se hizo más servil; la autoridad adquirió nuevas fuerzas frente a la experiencia. Los límites y el contenido de las disciplinas tradicionales, como la cosmografía o la filosofía, habían sido claramente señalados de acuerdo con los textos de la Antigüedad clásica, los cuales adquirieron aún mayor grado de autoridad cuando fueron reproducidos en letra impresa por primera vez" (Elliott 34). Varios autores insisten en afirmar que los lectores europeos no parecen haberse interesado con particular curiosidad en el mundo americano a lo largo del siglo XVI. Elliott acepta que no se dispone de datos estadísticos suficientes para confirmar esa apreciación; no obstante, considera que los estudios de Atkinson sobre el caso francés podrían ser considerados sintomáticos de la reacción de la comunidad de lectores europeos ante el acontecimiento americano y de la actividad editorial sobre literatura geográfica: "entre 1480 y 1609 fueron dedicados a los turcos y a Asia cuatro veces más libros que a América, y la proporción de libros sobre Asia aumentó en la década final del periodo citado" (Elliott 30). Antonello Gerbi anuncia un contraste entre el impacto que tuvo la noticia entre las personas ilustradas y entre el público general: "El interés relativamente escaso de la embrionaria opinión pública española ante los descubrimientos de las Indias, en contraste con la inmediata y apasionada reacción de toda la 
y las contradicciones de las informaciones geográficas respecto a la forma, la extensión y la ubicación de América en el mundo (expresadas ya sea a lo largo de los capítulos de una misma obra, como entre el texto principal y los mapas, o figuras incluidas) ${ }^{13}$.

La agregación de América en la sección final de los libros dedicados a la descripción o a la historia del mundo no fue una característica exclusiva de las obras clásicas editadas en el quinientos. Son muchos los textos renacentistas que, a fuerza de tener que reconocer la existencia de América, sin haber llegado a disipar muchas dudas sobre su naturaleza, apenas si adosaban una escueta mención sobre el Nuevo Mundo al final (ya sea un brevísimo capítulo, o solo un comentario marginal), en una suerte de apéndice complementario que venía a actualizar un modelo canónico, pero de ninguna manera alcanzaba a alterarlo. Ilustremos esta idea con la edición de Ioannis Honter Conornensis Rudimentorum Cosmographiae Liber Secundus, Generalis partium terre descriptio. Johannes Honter organiza el cuerpo de la obra a partir de la afirmación:

"Terrarum orbis in tres dividit partes. Europam, Asia \& Africa": sólo luego de una descripción de cada una de las partes, al final, se incluye Nomina insularum Oceani et maris [...] en la que se listan las siguientes islas: "Insulae septentrionales oceani prime sunt, Cassiterides, Inde Ibernia \& Britannia cum urbibus, Cantuaria, Londino \& Eboraco, Item Scotia, Orcades, Hemodes, Thule \& Scandia. In orientali Zipangri, Cingirma, Candin, Iava mayor \& minor, Sandur, Candur, Necura, Angama, Peutam, Seylam. In Australi, Iona,

Europa culta, ha sido ya observado con estupor varias veces" (Gerbi 143). En relación con los libros de geografía, Numa Broc ha sostenido que una obra como la Margarita Philosophica, de Georges Reisch (redactada hacia 1496 por el confesor del emperador Maximiliano y editada por primera vez en Estrasburgo en 1503), no solo no menciona los viajes portugueses, sino que retoma gran parte de las fábulas geográficas medievales sobre los monstruos y las zonas tórridas (Broc 18). Más específicamente en relación con los mapas y la fuerte inercia de los clásicos: "para los mapas impresos en el siglo XVI, las autoridades habían sido los trabajos de los geógrafos clásico: Ptolomeo, Estrabón, Pomponius Mela. Los mapas del mundo impresos en los primeros quince años [después del descubrimiento de América] guardaron más lealtad a Ptolomeo que a los descubrimientos, incluso cuando hacia el final de ese periodo de medio siglo, la Vittoria de Magallanes había dado la vuelta alrededor del mundo. Ptolomeo fue el cosmógrafo arquetípico y la codifición de las formas que el mapa del mundo -se suponía- debía tener siguieron sus instrucciones relativas al dibujo y a las proyecciones" (Woodward, Woodward, David 15).

13 En las obras clásicas editadas durante el quinientos, la presencia de América fue cobrando más importancia y protagonismo a lo largo de las sucesivas ediciones, en lo que podríamos denominar una "actualización progresiva". La obra De situ orbis, de Dionysius Periegetes, publicada en el Renacimiento, puede funcionar como un caso testigo de ello: la edición de 1534 incluye un globo que dejaba a la vista sólo un hemisferio: Europa, Asia y África. El mismo globo aparece tanto en la portada (página 65) como en la página 76, y son las dos únicas imágenes de la obra. 
Trapobana, Scoyra, Madagascar, Zanzibar. In occiduo, Dorcades, Hesperides, Fortunatae, America, Parias, Isabella, Spagnolla \& Gades. (Honter 91)

Una de las primeras menciones al estatus geográfico de América aparece en las Décadas de Orbe Novo, de Pedro Mártir de Anglería, y está referida a la controversial definición geográfica de Cuba. Como cabría esperar, él afirma que, dada su gran extensión, Cuba tenía que ser un continente y no una isla (aun cuando por entonces estaba ampliamente aceptado que se trataba de una isla).

Costeando derecho el litoral de la isla Juana, desde septentrión hacia occidente, navegó no menos de 800 millas. Pensando que 180 leguas se consideran un continente, porque no se veía ni un término, ni signo alguno de que la tierra terminara en lo que se ofrecía a su vista, decidió volverse. (Anglería 119)

Más allá de la argumentación geográfica, parece obvio que semejante afirmación pretendía reafirmar la tesitura colombina de que la Corona española había arribado a Asia. Sin embargo, América ha sido representada como una isla (lo que, según las categorías mencionadas, básicamente significaba que se trataba de tierra rodeada de agua) en muchas ocasiones, incluso desde tiempos muy tempranos.

En muchos mapas y libros del quinientos solo Sudamérica aparece como isla, desconectada de la Nueva España, y la actual América del Norte aparece como una prolongación de Asia. Si bien esto es, cuando menos, confuso (el actual istmo de Panamá era bien conocido desde, al menos, la segunda década del siglo XVI), hay que reparar en que esta configuración permitía conservar el esquema geográfico tradicional: si América estaba unida a Asia, el modelo geográfico podría ser conservado, ya que todas las partes seguían siendo piezas de una gigantesca masa terrestre. Pero si América estaba separada de Asia, entonces las cuatro partes no estarían compartiendo el mismo estatus, y ello, sin duda, representaría un complejo problema teorético.

Ciertamente, en los mapas del siglo XVI pueden reconocerse dos tipos de islas utilizados para representar América:

1. Una masa de tierra completamente rodeada de agua ${ }^{14}$.

2. Una masa de tierra "incompleta", que continúa más allá del mapa ${ }^{15}$.

14 Algunos de los mapamundi que representaron a América como una isla completamente rodeada de agua son: Martin Waldseemüller (1507), Coppo (1528), Benedetto Bordone (1528) y Sebastián Münster (1540), entre otros.

15 Algunos de los mapamundi que representaron a América como una isla "incompleta" son: Johannes Ryusch (1508) y Vesconte Maggiolo (1511), entre otros. 
Pensar América como isla fue, también, un modo de incluir el dato del "descubrimiento" dentro de un marco (conceptual, discursivo e intelectual) ya consagrado. De hecho, muchas islas habían sido añadidas desde el siglo XIV en los isolarios (libros de islas) ${ }^{16}$ : una variedad dinámica y creciente de islas podía ser adicionada, sin que ello perturbara ni el esquema ni el contenido de cada libro; el islario ofrecía un dispositivo eficaz y abierto para incorporar las noticias provistas en cada viaje de exploración. Y, desde luego, América es incorporada dentro de la categoría de isla. En la mayoría de los islarios - y también en otros textos-, América aparece incluida en un breve capítulo hacia el final del libro, una nota marginal o un apéndice agregado como para "actualizar" un corpus de información geográfica ya establecido ${ }^{17}$.

Al hacer encajar al Nuevo Mundo también se procuraba la continuidad de ese esquema intelectual que organizaba la geografía del mundo (el cual, por cierto, se mantiene casi inalterado, a excepción del desplazamiento desde el Mediterráneo hacia el Atlántico). Tanto Benedetto Bordone (1528) como Thomasi Porcacchi (repitiendo las palabras de Bordone, en 1572 y 1590) muestran a América como una isla más.

16 Los islarios que inventariaron y describieron las islas del Egeo y del Mediterráneo pueden remontarse hasta la Antigüedad clásica, pero, sobre todo, entre los siglos XIV y XVI adquieren un gran desarrollo. Algunos de los que más circularon fueron: De insulis et earum proprietatibus de Domenico Silvestri (1385-1406), Liber insularum Archipelagi del florentino Cristoforo Buondelmonti (ms, ca 1420), L'Arcipielgi, con tutte le isole de Marco Boschini (Venecia, 1658), Isolario dell'Arcipelago de Francesco Lupazolo (ms, 1638). Con la expansión de Europa, el género de los islarios también conoció una "expansión", manifestada en la voluntad de inventariar las islas del mundo entero. Aquí pueden citarse el Insularium illustratum del cartógrafo germano Enricus Martellus (ms, ca 1490), el mencionado Libro di tutte le isole del mondo de Benedetto Bordone (Venecia, 1528) — por cierto, más conocido que los anteriormente citados-, el Islario general de todas las islas del mundo de Alonso de Santa Cruz (ms, ca 1545), L'isole più famose del mondo de Tommaso Porcacchi (Venecia, 1572) y el Grand insulaire et pilotage del francés André Thevet (ms ca 1587). Sobre insularios, véase Donattini, Massimo. Spazio e modernità. Libri, carte, isolario nell'età delle scoperte. Bolonia, CLUEB, 2000, especialmente el capítulo "I libri delle isole" (167-192); también, Van Duzer.

17 Algunos ejemplos de ello son:

- Vadianus, Joachim (1534), Epitome trium terrae partium. América aparece mencionada al final,en la página 544, bajo el título: Insulae Oceani Praecipuae.

- Rithaymer, Georg (1538), Georgii Rithaymeri De orbis terrarum situ compendium: ad Hieronymun [sic] Vueyrer praepositum Reycherspergensem. Viena. En la última página (111), el breve apartado intitulado De terris et insvulis nuper repertis está prácticamente dedicado a América.

- Glareanus, Henricus (1543) Henricus Glareai, poetae laureati de geographia liber unus / ab ipso authore iam novissime recognitus. Basilea. 
Terra di Santa Croce, over mondo novo, fu la prima di tutte queste isole che tovata fusse, benche alchuni hebbono forma openione, che al nostro continente congionta fusse, nondimeno al presento possono esser certi, esser grandissima isola, percio che da uno capitano del re di Spagna una \& l'altra parte è stata veduta, ciò̀ la costa che verso tramontana è posta, \& láltra che all'ostro giace, alla quale per giorni sei passando monti valle \& fumi con l'essercito suo peruenne, Hor donque noi siamo certi esser isola \& non col nostro continente contenuta. (Bordone, Libro I, x).

Este parágrafo de Bordone llama la atención sobre la oposición entre las categorías isla y continente, y expone las diferentes opiniones respecto a la forma geográfica del Nuevo Mundo.

Más aún, si comparamos ese esquema de isla incompleta — tan familiar en los mapas del mundo que vieron la luz en las primeras décadas del siglo XVI- con el gráfico incluido en el libro de Apiano "para mostrar" cada uno de los cuatro tipos de tierras emergidas, veremos cuán similar aparece América respecto a la figura de continents.

A la luz de una comparación entre el modelo atribuido a la categoría de continente y lo que a primera vista parece ser un islote separado del mundo conocido (en mapas como los de la Margarita Philosophica, Contarini, Ruysch y Maggiolo), esa figura del Nuevo Mundo podría ser interpretada como un esfuerzo por engarzar esas tierras — que hasta entonces habian permanecido desconocidas-en el ecumene clásico. De hecho, algunos de esos mapas son ediciones de Ptolomeo (Sylvanus, 1511; Waldseemüller, 1513; Frisius, 1522) y otros están inspirados en proyecciones o informaciones geográficas tolemaicas (Reisch, 1503 y 1515), y esa América es identificada insistentemente como "Terra Sancta Crucis" (Contarini 1506, Ruysch 1507), un nombre que estaba aliado a las reivindicaciones lusitanas sobre Brasil ${ }^{18}$ y que desaparecería relativamente pronto —al menos, como topónimo principal-.

Sólo 15 años después de la noticia que llevó Colón a la península ibérica, el célebre mapa de Waldseemüller diseñaba por primera vez costas occidentales, y así inauguraba el periodo explícitamente "insular" para América.

18 En un libro muy raro (se supone que fue suprimido o prohibido), titulado Historia da provincia San [n]ta Cruz a qui vulgarme[n]te chamamos Brasil (1576), Pero de Magalhaes Gandavo relata el descubrimiento portugués de Brasil y su bautismo con el topónimo Santa Cruz. Consulté el ejemplar: Gandavo, Pero de Magalhaes (1576), Historia da provincia san[n]ta Cruz a qui vulgarme[n]te chamamos Brasil. Lisboa. 


\section{La isla que se transforma en pars}

La aparente incongruencia entre las tres partes del mundo conocido (que eran piezas de una única y enorme masa de tierra, en realidad, una gran masa de tierra a su vez rodeada por un gran océano) ya había sido advertida por Martin Waldseemüller en su monumental mapa de $1507^{19}$; y también se refería explícitamente a esta disparidad en su Cosmographiae Introductio: "Hunc in modum terra iam quadripartita cognoscitur; \& sunt tres primae partes cõtinentes: quarta est insula: cum omni quãq mari circũdata cõspiciatur" (Waldseemüller, cap. IX).

Pero aun cuando América fuera una isla, su enorme tamaño era un argumento para sostener la idea de que debía ser considerada una parte más, similar o equivalente a las otras tres. La alusión al descomunal tamaño ha sido ampliamente señalada por los escritores de la época ${ }^{20}$ (por lo que la siguiente cita es solo un ejemplo sintomático de una situación generalizada):

De la quarta parte del mundo llamada nuevo mundo

Al Occidente del Aphrica y de Europa está la quarta parte de la tierra, y su división a quién llamamos mundo nuevo, y con razón porque esta tierra no procede de alguna de las tres que ya nombramos, sino sola por si esta distincta y apartada dellas. Y llamase nueva tierra por razón que nunca los antiguos tuvieron noticia cierta Della, hasta que el año de mil y cuatrocientos y noventa y dos fue descubierta por Cristóbal Colon. Esta tierra y parte del mundo no da ventaja en grandeza, población y riqueza a cualquiera de las tres ya dichas, antes osaría afirmar que vence en riqueza a todas tres juntas. (Chaves 65; cursivas mías)

Incluso cuando había dudas sobre si América era una isla, lo que sí parecía evidente es que merecía ser considerada como un lugar. A menudo, el argumento del tamaño (que por sí mismo parecía justificar que el Nuevo Mundo era otra parte)

19 Es un mapa grabado en madera sobre papel, en 12 hojas para ser unidas. Sus medidas son 13,2 x $236 \mathrm{~cm}$. Ha pasado a la historia por ser el mapa que acuñó el nombre de América para el Nuevo Mundo.

20 En la Cosmographia incluida en Novus orbis regionum ac insularum veteribus $i$ cognitarum / una cum tabula cosmographica, \& aliquot alijs consimilis argume ti $l$ bellis, quórum omnium catalogus sequenti patebit pagina (Basilea, 1537, editada por Simon Grynaeus) se incluye el siguiente texto de Sebastián Münster: "Quin $\&$ in oceano occidentali feré novus orbis nostris temporibus ab Alberico Vesputio \& Christophoro Columbo, multis \& alijs insignibus uiris inuentus est, qui non absre quarta orbis pars nuncupari potest, ut iam terra non fit tripartita, sed quatripartita, quum hae Indianae insulae sua magnitudine Europa excedant, praesertim ea quam ab Americo primo inventore Americam vocãt" (fol. 4) (los destacados son mios). 


\section{FRONTERAS}

de la histaria

fue reforzado con la idea de que el Nuevo Mundo tenía una esencia diferente ${ }^{21}$, del mismo modo como las otras tres partes eran diferentes entre sí.

Sin embargo, todavía quedaba sin resolver el asunto del estatus geográfico del Nuevo Mundo. En otras palabras: si América era una isla no podría ser considerada una parte (¿una parte de qué?). Pero si era tan grande (incluso más que algunas de las otras ya conocidas) tenía que ser una parte. Las categorías existentes no resolvían el problema que América estaba planteando...

\section{Mapa 1. La cosmographia de Pedro Apiano}

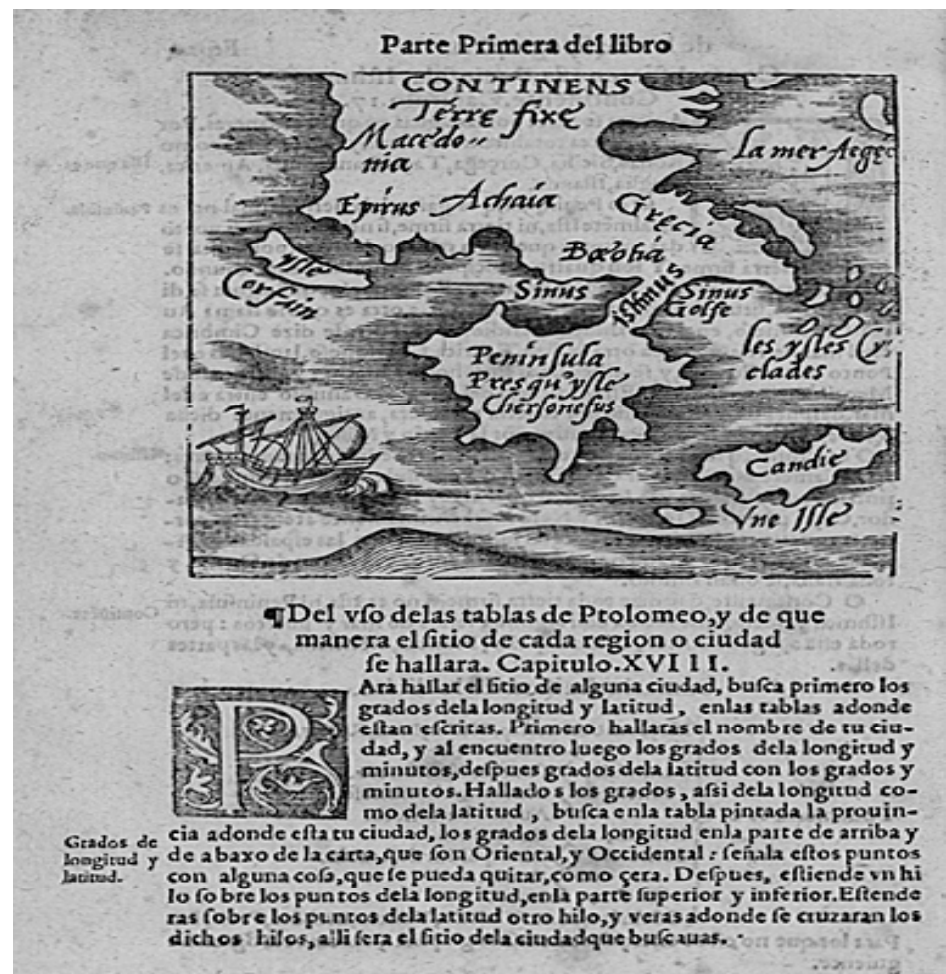

Fuente: La cosmographia de Pedro Apiano / corregida y añadida por Gemma Frisio... 1575.

$\overline{21}$ Francisco López de Gómara, en la dedicatoria a Carlos V con la que abre su Primera y segunda parte de la historia general de las Indias con todo el descubrimiento y cosas notables que han acaecido desde que se ganaron para el año de 1551 con la conquista de México y de la Nueva España, dice: "Y assi las llaman mundo nuevo, y no tanto le dizen nuevo por ser nuevamente hallado quanto por ser grandissimo. Y casi tan grande como el viejo, que contiene a Europa, Africa y Asia. Tambien se puede llamar nuevo por ser todas sus cosas diferentísimas de las del nuestro". 


\section{Americae pars se transforma en continente}

Desde un punto de vista estrictamente geográfico, la hipótesis de la conexión entre América y Asia proponía que la primera era una prolongación de la segunda $-\mathrm{y}$ que ambas estaban conectadas por un estrecho sendero de tierra similar a un istmo-, y así permitía mantener la vigencia de los viejos conceptos geográficos (isla, istmo, continente y península) para describir la geografía del mundo. $\mathrm{Cu}$ riosamente, tanto la existencia de un istmo que conecta dos porciones de masas terrestres como los conceptos geográficos referidos fueron también utilizados para negar la insularidad de América del Sur: aun cuando América fuera pensada como una isla, el istmo de Panamá articularía dos partes de un mismo continens.

Y así se entenderá el Perú [como] todo lo que hay desde el Estrecho de Magallanes hasta la ciudad de Panamá, donde esta tierra viene a estrechar tanto que no tiene de ancho más de diez y siete leguas, contando de Panamá, que cae en el Mar del Sur hasta el otro Cabo en el mar del Norte que llaman Nombre de Dios, por lo cual el Perú deja de ser isla. Por la Nueva España se entenderá todo lo demás que hay desde Panamá hasta la última Tierra de Bacallaos, en el Mar Helado, dicho Hyperboreo, en la parte del Norte. (Apiano y Frisius, 1575; cursivas mías)

Este interés por negar el estatus de isla asignado a América durante tantas décadas parece haber tenido no solo implicaciones de orden científico (más bien, geográfico), sino también, de orden moral. En palabras de Lestringant: "Les temps des îles, qui s'étire au long du XV siècle, sera suivi d'un temps des continents. Les îles à la Renaissance vont progressivement perdre de leur prestige, dès lors qu'elles apparaissent comme le simple prélude à de plus amples découvertes. [...] L'opposition est géographique, mais aussi morale : contrairement aux îles inconstantes, la terre ferme tient ses promesses" (4). Efectivamente, las islas parecen haber funcionado como un dispositivo intelectual eficaz para la construcción simbólica de la geografía imaginaria ${ }^{22}$, y, durante algún tiempo y en ciertos contextos, América pudo ser acoplada sin profundas revisiones.

22 Muchos especialistas han abordado, desde distintos ángulos, esta dimensión intelectual de las islas en la modernidad temprana. Cosgrove lo expresa así: "las islas del Renacimiento complementaban los interiores continentales como espacios liminales donde el orden social europeo podía ser invertido" (Cosgrove, Denis. Apollo's eye. A cartographic genealogy of the Earth in Western imagination. Baltimore: The Johns Hopkins University Press, 2001, p. 95). Véase también Jacob, pp. 197-201, y Pelletier, Monique (eds.)., Géographie du Monde au Moyen Age et à la Renaissance. París: Editions du Comité des Travaux Historiques et Scientifiques, 1989. 
Ante la otra hipótesis, es decir, ante la posibilidad de que América (del Norte) estuviera separada de Asia, el istmo de Panamá adoptó una función análoga a la que habría tenido la conexión entre América y Asia. De esta manera parecía resuelto el conflicto teorético: el istmo de Panamá une dos partes, una meridional y otra septentrional, por lo que el Nuevo Mundo se vuelve un continente en sí mismo.

S'estende dal Norte, nel che risponde co'l nostro Orbe, nella medesima ampiezza, stringendosi sempre, che scorre à mezzogiorno la volta di Ponente, infin che arriva in quel pasese, che propiamente gli Spagnoli chiamano Terra ferma, dove giace cosi stretta frà due mari, cioè l'Oceano del Norte, che risguarda l'Africa, e quello del Sur, ilquale s'oppone all'incontro della Meridional parte del'Asia, che pare che si distacchi in due grand'isole, detta l'una settentrionale e l'altra chiamata Australe, poiche l'isthmo co'l quale si rende l'una e l'altra un continente. (Aniana 351; destacados míos)

De hecho, esa división ya había sido cartografiada por Mercator en su mapa doble hemisferio de 1538. En ese mapa puede verse no solo que América está completamente separada de Asia, sino que aparecen claramente identificadas Americae Pars Meridionales y Americae Pars Septrentrionales. Sin embargo, habrá que esperar hasta la aparición del atlas orteliano, cuya primera edición data de 1570 (es decir, más de 30 años más tarde) para que esto vuelva a figurar en un mapa.

\section{Cuando las partes se transforman en continentes}

Hasta aquí nos hemos ocupado solo de una parte del problema implicado en la reconsideración conceptual de las categorías vigentes para describir las tierras emergidas en la modernidad temprana. En realidad, la discusión sobre el estatus geográfico del Nuevo Mundo, y, en particular, la polémica en torno a la dicotomía isla/continente, implicaba también una revisión de los modos de pensar el Viejo Mundo. Por lo tanto, suponer que la diferencia entre isla y continente "sólo reside en el empleo que hacen de estos conceptos quienes los utilizan" (Randles 130) enfatiza demasiado la casuística del uso y desmerece la concomitante (y novedosa) preocupación explícita por definir un campo conceptual coherente. Aquí, en cambio, se pretende destacar la impronta que esta preocupación dejó en el campo de las ideas geográficas.

En este sentido, interesa destacar que esa discusión instaló el debate sobre los límites que separaban cada una de las partes. Y el criterio para demarcar las partes recayó privilegiadamente sobre cuerpos de agua (ríos, mares y océanos) que marcaban las discontinuidades de la masa terrestre. 
$\mathrm{Y}$ de estas dos partes [Oriente y Occidente] digo que la parte de Oriente se divide en cuatro partes que son: Asia y la India Oriental y África y Europa. A Asia divide de Europa el río Tanais, que entra en la laguna Meotidis, que es en el mar Euxino: y a Asia y a África divide el río Nilo que entra en Alexandría; y a Asia divide de la India un río que está en fin de la tierra de Persia, que entra en el mar Pérsico. (Enciso 119)

Los cuerpos de agua, que tradicionalmente habían sido considerados como elementos diferenciadores entre las partes, se transformaron en un criterio cada vez más imperativo. En este sentido, cuanto más grandes y evidentes fueran, mejor cumplirían la función de separar masas terrestres diferenciables: "Ici il faut noter que plusieurs auteurs ont mis le Nil pour le terme divisant l'Asie et l'Afrique. Mais ceux qui reprend Ptolomee, disant être meilleur le diviser par mer toutes \& quantes fois que l'on peut, que par riviers ou fleuves" (Focard 151; destacados míos).

En este contexto, desde mediados de siglo las descripciones de los continentes que habían sabido empezar por una descripción de sus raíces mitológicas ya no empiezan tanto por una etimología de sus nombres como sí por la demarcación de sus límites y, por tanto, de los alcances geográficos de cada una, con relativa independencia de la forma que tuvieran. En ese desplazamiento se diluye la diferencia entre los orígenes mitológicos de las tres partes tradicionale ${ }^{23}$ y el origen "moderno" del nombre de la cuarta parte, y se va construyendo la identidad geográfica del Nuevo Mundo.

Es sabido que los mapas renacentistas no incluían líneas divisorias, por lo que esa preocupación por establecer una línea cartografiable que discrimine dos unidades geográficas diferentes era una forma novedosa de pensar la geografía. El efecto más evidente que tuvo esto es que cada una de las partes, al estar encerrada por agua, devenía... en una isla.

De las tres partes de la Tierra firme la Asia tiene sus términos con la África en aquella parte de la Arabia petrea junto al Nilo, y con la Tierra Incognita a la cual el Mar Índico rodea. Con la Europa tiene sus confines en aquella parte

23 El mencionado libro de Apiano y Frisius que decía que América tomaba el nombre de su descubridor, describe de la siguiente manera el origen mitológico de las otras partes: "Europa tomó su nombre de una hija de Ageno, rey de Fenicia, la cual fue raptada por Júpiter, desde África fue llevada a Candia. [...] África, a la cual los griegos dijeron Libia (como lo cuenta Josefa en su libro de las antigüedades) tomó nombre de un descendiente de Abraham y de Cethura su mujer, el cual vino a Libia con ejército: y después que venció a sus enemigos, puso en ella su asiento" (Apiano y Frisius 32 recto -33 verso). 
que es entre la laguna Meotide y el Oceano Sarmático, sobre la corriente del río Tanais, que entra en la sobredicha laguna. La África y la Europa son separadas por el Estrecho de Gibraltar. Así que la Asia participa de los confines y términos de ambas dos, y cada una de las otras por sí, no, sino que participan solamente de los términos de la Asia y en lo de más son por todas partes rodeadas del Mar, y con casi como islas. (Girava 58; cursivas mías)

La reformulación de los conceptos básicos que servían para organizar la geografía del mundo implicó el fin de la dicotomía entre isla y continente. Isla y continente dejaron de ser considerados dos conceptos excluyentes. La antigua idea de pars comenzó a ser reemplazada por la de continente, aunque, por cierto, cuando ello no implicó de modo alguno que se le atribuyera un sentido único e inequívoco al término continente ${ }^{24}$.

\section{Conclusiones. De partes y continentes: la emergencia de los conceptos de la geografía moderna}

El descubrimiento europeo de América ha sido examinado desde múltiples ángulos. Desde una perspectiva cercana a la historia de las ideas y a la historia de la ciencia, hemos procurado conectar la experiencia intelectual desatada por la aparición de América con la emergencia de un nuevo modo - podríamos decir "moderno"- de pensar la geografía del mundo, encarnada en la búsqueda de un andamiaje conceptual coherente para dar cuenta de las nuevas configuraciones geográficas.

La aparición de América obligó a reconsiderar el significado de cada una de las partes del mundo y, con ello, el criterio aplicable para definir cada una de ellas. Si la idea de pars había funcionado como un modo de pensar las cuatro partes del mundo a partir de categorías equivalentes, ello se debía a que el hecho de ofrecer un criterio aplicable a cada una de las cuatro partes de manera análoga tenía la virtud de lograr una armoniosa incorporación del Nuevo Mundo en un esquema

24 Martin Lewis y Kären Rigen citan algunos textos que muestran la persistencia del modelo dicotómico basado en la oposición Nuevo-Viejo Mundo para pensar la categoría de continente. Así nos recuerdan que Emmanuel Bowen afirmaba en 1752 que "a continent is a large space of dry land comprehending many countries all joined together, without any separation by water. Thus Europe, Asia, and Africa is one great continent, as America is another" (citado en Lewis y Wigen 29). Y todavía en 1971 el Oxford English Dictionary sostenía que "Formerly two continents were reckoned, the Old and the New; the former comprising Europe, Asia, and Africa, which form one continuous mass of land; the latter, North and South America, forming another. These two continents are strictly islands, distinguished only by their extent. Now it is usual to reckon four or five continents, Europe, Asia, Africa, and America, North and South; the great island of Australia is sometimes reckoned as another" (29). 
geográfico más amplio. Pero las categorías geográficas (basadas en ciertas propiedades morfológicas) que hasta entonces habían sido utilizadas para describir cada una de las partes del mundo pronto mostraron sus límites y sus contradicciones.

En ese contexto, la idea de pars fue progresivamente reemplazada al mismo tiempo que se consolidaba una reactualización semántica del término continente. Este último absorbió la noción de porción o elemento de un sistema mayor (el ecumene) implícita en pars e incorporó nuevos elementos geográficos como marcas definitorias (por ejemplo, las divisiones o los límites).

En lugar de detenernos en analizar exclusivamente si América fue pensada como una isla o como un continente, optamos por encuadrar esa polémica en los intentos de sistematización de las categorías geográficas que formaban un andamiaje interpretativo amplio, porque entendemos que ese debate revela una dimensión del descubrimiento europeo de América menos atendida: las estrategias intelectuales que los europeos tuvieron que poner en juego no solo para comprender la naturaleza del Nuevo Mundo, sino también para reconsiderar la naturaleza del Viejo Mundo y, más ampliamente, para repensar el mundo entero.

La trascendencia de este proceso de redefinición conceptual puede verse en la vigencia que tiene, aún en nuestros días, la arquitectura continental como patrón de organización de la geografía del mundo. En efecto, resulta sorprendente la permanencia que ha tenido como modelo de distribución geográfica en la identificación de las tierras emergidas: más allá de las alteraciones y los ajustes a los que la noción de continente fue sometida durante los siguientes 400 años, la idea de continente se ha transformado en una categoría primaria y englobante, que incluye todo tipo de masas terrestres (tierra firme, penínsulas, istmos e islas). Dicho de otro modo, la discusión sobre la naturaleza geográfica de América apenas fue el punto de partida de una reconsideración conceptual más extensa, que forma parte de un proceso vigente, el cual continúa aún su dinámica, a tal punto que el concepto de continente sigue siendo revisado (solo hay que pensar en los polémicos casos de Australia y la Antártida) y puesto en discusión en nuestros días. 


\section{Bibliografía}

\section{Fuentes primaria}

Anglería, Pedro Martir de. De Orbe Novo. Buenos Aires: Alción Editora, [1511] 2004.

Aniana, Giovanni Lorenzo. L' universale fabrica del mondo, ouera Cosmographia. Dell'Ecc Gio. Lorenzo d'Aniana. Divisa in Quattro tratati: Ne' quali distintamente si misura il Cielo, e la Terra \& si descrivono particolarmente le Provincie, Città, Castella, Monti Mari, Laghi, Fiumi \& Fonti. Et si tratta delle Leggi \& Costumi di molti Popolo, de gli Alberi, \& dell'Herbe e d'altre cose pretiose \& Madicinali \& de gl'inventori di tutte le cose. Di nuovo ornata con le difurre delle quattro parti del Mondo in Rame, et dal medesimo auttore con infinite aggiuntioni per ogni parte dell'opera ampliata. Nápoles. John Carter Brown Library, [1573] 1596.

Apiano, Petrus y Gemma Frisio. La cosmographia de Pedro Apiano / corregida y añadida por Gemma Frisio, medico y mathematico; La manera de descriuir y situar los Lugares, con el Vso del Anillo Astronómico, del mismo autor Gemma Frisio; El Sitio y Descripcion de las Indias y Mundo Nueuo, sacada de la Historia de Francisco Lopez de Gomara, y de la Cosmographia de Ieronymo Giraua Tarragonez. Amberes, 1575.

Bordone, Benedetto, Isolario di Benedetto Borndone, nel qual si ragiona di tutte l'isole del mondo, con li lor nomi atichi \& moderni, historie, favole \& modi del loro vivere, \& in qual parte del mare stanno \& in qual parallelo \& clima giaciono. Con la gionta del Monto del Oro novamente ritrovato. Con el breve del Papa. Et gratia \& rpivilegio della Illustrissima Signoria di Venetia come in quelli appare. MDXXXIIII. Venecia, 1534.

Chaves, Jerónimo de, Chronographia o repertorio de los tiempos el mas copioso y preciso que hasta agora ha salido a luz. Sevilla, 1561.

Enciso, Martín Fernández de. Suma de Geographia [Edición de Mariano Cuesta Domingo]. Madrid: Museo Naval, [1519] 1987. 
Focard, Jacques. Paraphrase de l'astrolabe, contenant les principes de geometrie. La sphere. L'astrolabe, oi, declaration des choses celestes. Le miroir du monde, ou, exposition des parties de la terre. Lyon, 1546.

Girava, Jerónimo. Dos libros de Cosmographia. Compuestos nuevamente por Hieronymo Girava Tarragones, s.l. 1556.

Porcacchi. L'isole piu famose del mondo / descritte da Thomaso Porcacchi de Castiglione arretino; e intagliate da Girolamo Porro Padovano. Venecia, [1572] 1590.

Waldseemüller, Martin. Cosmographiae Introductio cvm qvibvs dam Geometriae ac Astroso Miae Principiis ad Eam Rem Necesariis. Insuper quattor Americi Vespucii navigationes. Universalis Cosmographiae descriotio tam in solido plano / eis etiam insertis quae Ptolomeo ignota a nuperis reperta funt. Disthycon. Cum deus astra regat / \& terrae climata Caesar Nec tellus / nec eis sydera maius habent, s.1. 1507.

\section{Fuentes secundarias}

Broc, Numa. La géographie de la Renaissance. París: Comitè des Travaux Històriques et Scientifiques, 1980.

Brotton, Jerry. Trading Territories: Mapping the Early Modern World. Londres: Reaktion Books, 1997.

---. El bazar del Renacimiento: Sobre la influencia de Oriente en la cultura occidental. Barcelona: Paidós, 2002.

Cosgrove, Denis. Apollo's Eye. A Cartographic Genealogy of the Earth in Western Imagination. Baltimore: The Johns Hopkins University Press, 2001.

Donattini, Massimo. Spazio e modernità: Libri, carte, isolario nell'età delle scoperte. Bolonia: CLUEB, 2000.

Elliott, John. El Viejo Mundo y el Nuevo. (1492-1650). Madrid: Alianza, [1972] 1990.

Gerbi, Antonello. La naturaleza de las Indias nuevas. De Cristóbal Colón a Gonzalo Fernández de Oviedo. México: Fondo de Cultura Económica, 1975. 
Jacob, Christian. L'empire des cartes: Approche théorique de la cartographie à travers l'historie. París: Albin Michel, 1990.

Lestringant, Frank. "La voie des îles”, Medievales, 47 (2004). 30 de abril. <http:// medievales.revues.org/document506.html>.

Lewis, Martin y Rigen, Kären. The Myth of Continents: A Critique of Metageography. Berkeley: University of California Press, 1997.

Livingstone, David. The Geographical Tradition. Oxford: Blackwell, 1992.

Nebenzhal, Kenneth. Atlas de Colón y los grandes descubrimientos. Madrid: Magisterio, 1990.

Parry, John. El descubrimiento del mar. Barcelona: Crítica, [1974] 1989.

Pelletier, Monique (ed.). Géographie du Monde au Moyen Age et à la Renaissance. París: Editions du Comité des Travaux Historiques et Scientifiques, 1989.

Randles, W.G.L. De la tierra plana al globo terrestre: Una rápida mutación epistemológica, (1480-1520). México: Fondo de Cultura Económica, [1980] 1990.

Relaño, Francesc. The Shaping of Africa: Cosmographic Discourse and Cartographic Science in Late Medieval and Early Modern Europe. Surrey: Ashgate, 2002.

Said, Edward. Orientalismo. Madrid: Debate, [1978] 2002.

Shirley, Rodney. The mapping of the world: Early printed world maps (14721700). Londres: Holland Press, 1983.

Thrower, Norman. Maps and civilization: Cartography in culture and society. Chicago: University Chicago Press, 1996.

Van Duzer, Chet. "From Odysseus to Robinson Crusoe: a survey of early western island literature". Island Studies Journal, 1.1 (2006) 143-162.

Vargas Martínez, Gustavo. Atlas antiguo de América. Siglos XV y XVI. México: Trillas, 1995. 
Vignolo, Paolo. L'Europe à l'envers: les antipodes dans l'imaginaire de la Renaissance. Tesis doctoral. Paris: École des hautes études en sciences sociales, 2003.

Whitfield, Peter. The Image of the World: 20 Centuries of World Maps. California: Pomegranate Artbooks, [1994] 1996.

Wintle, Michael. "Renaissance Maps and the Construction of the Idea of Europe". Journal of Historical Geography 25.2 (1999) 137-165.

Wolff, Hans (ed.). America. Early Maps of the New World. Munich: Prestel, 1992.

Woodward, David. Maps as Prints in the Italian Renaissance: Makers, Distributors and Consumers. Londres: The British Library, 1995.

Fecha de recepción: 16 de mayo de 2008

Fecha de aprobación: 25 de septiembre de 2008 